\title{
The Appropriateness of Using the Self-Directed Search Questionnaire in Developing Countries: A Pilot Study with South African Navy Divers
}

\author{
Charles H. Van Wijk, Marilize Fourie \\ Department of Psychology, Institute for Maritime Medicine, Simon's Town, South Africa \\ Email: chvanwijk@gmail.com
}

How to cite this paper: Van Wijk, C.H. and Fourie, M. (2017) The Appropriateness of Using the Self-Directed Search Questionnaire in Developing Countries: A Pilot Study with South African Navy Divers. Open Journal of Social Sciences, 5, 60-69. https://doi.org/10.4236/jss.2017.52007

Received: January 4, 2017

Accepted: February 4, 2017

Published: February 7, 2017

Copyright (c) 2017 by authors and Scientific Research Publishing Inc. This work is licensed under the Creative Commons Attribution International License (CC BY 4.0).

http://creativecommons.org/licenses/by/4.0/

\begin{abstract}
In contested labour markets in developing countries, vocational interest inventories could potentially match applicants to speciality occupations. This descriptive study investigated the appropriateness of career interest, represented by the SDS, to guide vocational placement in a developing country. The study applied Holland's concepts of congruence, differentiation, and consistency of vocational profile to South African Navy divers as a case study. The 81 navy divers generated an S/R/E code, but with questionable congruence, and poor differentiation and consistency. The results suggested that the profile might reflect socio-economic dynamics rather than the expression of personality-vocational matching, and such scales might not be useful for vocational placement in local environments. The study cautions the use of vocational guidance instruments in context of developing countries, where socio-economic considerations may outweigh personality characteristics in career choices.
\end{abstract}

\section{Keywords}

South Africa, Navy Diving, Career Motivation, Vocational Placement, Developing Countries, Socio-Economic Status

\section{Introduction}

The concepts of vocational interest and personality, and the instruments to measure it, are useful in guiding appropriate career placement. However, in developing countries, other factors are also important when determining career choices, for example, socio-economic circumstances. This paper presents an exploratory pilot study that investigated the appropriateness of career interest, represented by the Self-Directed Search Questionnaire (SDS), to guide vocational placement in a developing country, using South African Navy (SAN) di- 
vers as a case study.

Holland's SDS was used because it is considered one of the most widely used vocational interest inventories [1], translated into over 25 languages, used by more than 35 million worldwide [2], and is also very popular in South Africa (SA) [3]. However, there have been concerns regarding the appropriateness of its 3-digit code in SA [4]. There are further inconsistent reports on its usefulness with military occupations [5] [6].

\subsection{Background to the SDS}

The SDS is based on Holland's RIASEC theory, which in turn is based on a number of foundational principles, including that career choices could be seen as an expression of personality, and that interest questionnaires can be seen as inventories of personality [7].

Holland described six personality types and six corresponding working environments, namely Realistic (R), Investigative (I), Artistic (A), Social (S), Enterprising (E), and Conventional (C). The six types have been positioned on a hexagonal model that explains the relationship of the personality and environmental types to each other in terms of Holland's secondary constructs. Individuals are described by using the three highest or most dominant personality types that emerge during assessment. The SDS generates a three-letter code that can be matched to occupational environments with identical or similar codes. The ideal is to match an individual's three-letter code to a corresponding three-letter code for a specific work environment [4]. However, Holland did note that all types are present in all work.

Holland further developed a number of secondary constructs [4] [7], of which three was used in the current study:

Congruence refers to the relationship of the personality to the environment. It is determined by comparing the three-letter personality code obtained on the SDS with the three-letter occupational code obtained from a dictionary of occupations. Increased difference between the codes of the person and the environment decreases congruence.

Differentiation refers to how close scores on the different personality types are to each other. This can be calculated in multiple ways. A high number is indicative of good profile differentiation, which makes career choice easier.

Consistency refers to the degree of internal agreement, in how close letters are to each other on the hexagon as measured by the SDS. Greater profile consistency is associated with more predictable career choices.

The SDS was adapted and standardised for SA use [8], and a SA version of Holland's Dictionary of Occupational Codes, known as the South African Dictionary of Occupations (SADO) was also developed [9]. The SADO has no reference to navy divers; however, a number of potentially related occupations are listed, for example blaster (RCI/E), deckhand (RCI/E), rigger (RCI/E), and seaman (RCE). In each case the RC combination appears prominent. Non-South African sources also provide related occupations, e.g. commercial diving (RE) 
[10] and underwater demolition (RI) [11].

\subsection{South African Context}

Employment situation. The opportunities for career choices in a developing country like SA, based on codes like those provided by the SDS, are tempered by the local employment situation. The current expanded unemployment figure is $36 \%$ [12], potentially resulting in young people seeking employment based on opportunity rather than field preference.

This leads to situations like, for example, the KZN Traffic Department who in December 2012 offered 90 posts for trainees, and received 170,000 applications, of whom 34,000 qualified to apply. The subsequent selection resulted in the tragic deaths of eight young people, which were widely reported in the media [13].

SA navy recruitment. The SAN actively recruits across all nine provinces, also targeting schools in remote rural areas [14], thereby opening up career opportunities that such communities would otherwise not be exposed to. Appointments are made to be representative of province, race, and gender. The SAN receives in excess of 15,000 applications for 500 positions each year [14]. Diver recruitment is specifically done across provinces and gender groups, and actively promoted to communities with historically poor access to this career field.

SA navy diving. The SAN employ divers in various capacities. They may be engaged in routine duties such as harbour searches and retrieval of equipment from the sea, or be involved in deep diving activities, using mixed gases, underwater tools, and explosives. They are also involved in search and rescue operations. SAN divers undergo extensive training in both diving procedures and the equipment required for tasks underwater [15]. All training is done in English, which is also the lingua franca in the workplace. SAN divers tend to conform to a typical personality profile [16].

No formal work studies on navy divers could be located in preparation of this paper. However, based on the above, navy diving can be considered a typical $\mathrm{R}$ environment. R environments are summarised [7] [8] [17] as often physically and technically demanding and traditionally characterised as involving masculine tasks, requiring the utilisation of machines and tools, and fostering technical competency. Typical occupations for realistic types include defence force personnel, technicians, and heavy machinery operators.

It could then be expected that $\mathrm{R}$ personality types would find themselves in the SAN diving environment. $\mathrm{R}$ types are summarised [7] [8] [17] as preferring realistic occupations or situations requiring manual activities and the manipulation of objects, machinery, or tools. They are usually physically robust and tend to approach difficulties in a systematic, problem-solving manner. $\mathrm{R}$ types tend to avoid the kind of activities typical to $S$ occupations or situations, preferring to work with other realistic individuals or on their own.

\subsection{Rationale and Aim}

Given the potentially large numbers of applicants for SAN diving, assessment of 
the fit between individuals and career fields may be useful to guide placement into the navy diving environment. The SDS could be considered, if it is found appropriate for the task. However, it is not clear what the ideal SAN diving type code would be, or even whether the SDS, given the concerns regarding its use in SA and in military occupations, will be able to generate an useable personenvironment code to guide vocational placement. This study aimed to investigate the appropriateness of career interest, as represented by the SA version of the SDS, to guide vocational placement. It applied Holland's concepts of congruence, differentiation, and consistency of vocational profile to the SAN diving environment. Being exploratory in nature, this pilot study used a quantitative, descriptive design.

\section{Method}

\subsection{Participants}

Active duty SAN divers were invited to participate if they met the following criteria: a) completed a minimum of two years operational experience, which served as an indication of their ability to adjust into that vocation, and b) had no psychiatric or psychological history affecting their work during that time. Participants completed an information and consent form, and then the SA version of the SDS [8], in small groups. Where time permitted, a brief interview was conducted with each participant where they were asked to recall the reasons for choosing navy diving as a career. Due to time constraints only 59 interviews were concluded. The study was conducted according to the principles in the Declaration of Helsinki of 2013.

The sample consisted of 81 clearance divers ( 10 women, 71 men), aged 22 to 32. They had all completed between two and 10 years as active duty divers. Of the sample, 56.8\% completed the SDS in their first language, while $43.2 \%$ completed it in their second language. All were in possession of a National Senior Certificate. Twelve of the divers were classified as senior divers, with a minimum of six years operational diving. Senior diver status is the product of both experience and qualification.

\subsection{Instrument}

The SA version of the SDS measures occupational interest, knowledge competencies, attitudes, and perceived abilities across the six fields of interest [8]. An individual's responses are used to create a 3-digit code, which reflects occupational types according to Holland's personality typology. High internal consistency reliabilities have been reported, as well as good concurrent and predictive construct validity [7] [8]. The SA version, while somewhat dated, was used due to local ethical requirements.

\subsection{Data Analysis}

SDS codes for navy divers are reported in terms of means and standard deviations per type, ranked sequentially by highest score, and combined into a 3-digit 
code, as well as in terms of frequencies of endorsed fields, through percentages in the top three positions. Language and seniority groups were compared using a t-test for independent samples. Profiles of mean scores for the total group, and junior and senior diver subgroups, are presented graphically.

Congruence was examined by comparing the 3-digit personality code obtained on the SDS with the 3-letter occupational code obtained from related occupations in the SADO. Differentiation was calculated-following the SA Manual [8] - by subtracting the lowest type score from the highest, and used Holland's standard error of difference, namely 8 [18].

Consistency was determined by examining the hexagonal location of the letters of the personality code.

\section{Results}

\subsection{Profile Code}

The means and standard deviations for the six personality types are presented in Table 1. This indicates a 3-digit personality code of S/R-E (letters separated by a forward slash can be presented in any order). The profile is graphically represented in Figure 1.

Table 1. Descriptive statistics for the six personality types $(\mathrm{N}=81)$.

\begin{tabular}{|c|c|c|c|c|c|}
\hline & \multirow[t]{2}{*}{ Mean } & \multirow[t]{2}{*}{ SD } & \multirow[t]{2}{*}{ Range } & \multicolumn{2}{|c|}{ Frequency* } \\
\hline & & & & $\mathbf{N}$ & $\%$ \\
\hline $\mathrm{R}$ & 27.4 & 9.6 & $5-45$ & 62 & 22.4 \\
\hline I & 21.9 & 9.4 & $4-43$ & 32 & 11.6 \\
\hline A & 19.4 & 10.7 & $2-48$ & 25 & 9.0 \\
\hline$S$ & 27.7 & 8.4 & $13-46$ & 78 & 28.2 \\
\hline $\mathrm{E}$ & 24.2 & 8.8 & $10-46$ & 56 & 20.1 \\
\hline $\mathrm{C}$ & 20.4 & 8.9 & $4-44$ & 24 & 8.7 \\
\hline
\end{tabular}

*Endorsement of personality types by percentage in top three positions.

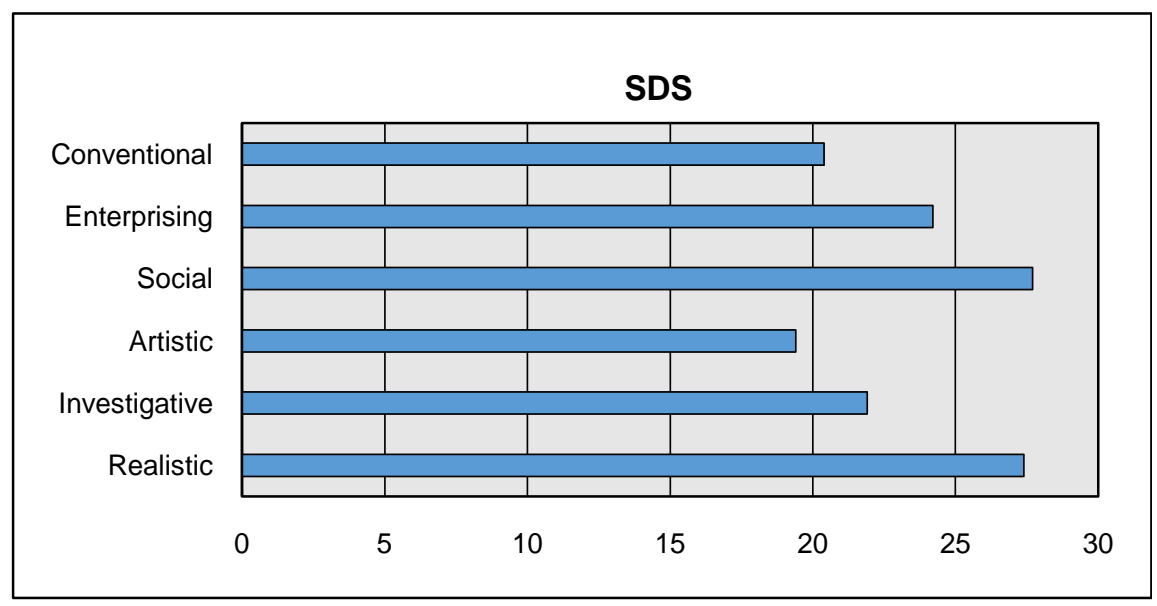

Figure 1. Personality type profiles for navy divers. 
There was some difficulty in presenting a frequency table due to the high number of tied scores $( \pm 10 \%)$ for the highest type. In spite of this, the highest fields by percentage in the top three positions generated a 3-digit personality type code of S-R/E (see Table 1 for distribution).

The position of S (and to some extent $\mathrm{C}$ and I) appeared at odds with the expectation from related occupations in the SADO. This may suggest sub-optimal congruence, but such interpretation must be tempered by the low differentiation reported. In this sample there was little difference between mean scores across the six types (with the maximum difference only 8.3), indicating poor differentiation. Consistency was also low, with S and R located at opposing sides of Holland's hexagon.

\subsection{Language and Seniority Sub-Group Differences}

Comparative statistics can be found in Table 2. There were no statistically significant difference between the language sub-groups; senior divers scored significantly lower on A and S than junior divers. Figure 2 graphically presents the profiles of junior and senior divers. The profile of the senior divers appears somewhat more differentiated (namely, R-S/E/I).

\subsection{Interview Results}

The recalled motivations for choosing navy diving as career comprised three categories. The first category of divers $(\mathrm{N}=13)$ reported being interested in navy

Table 2. Subgroup comparison using t-tests for independent samples.

\begin{tabular}{|c|c|c|c|c|c|c|c|}
\hline & Mean & $\mathrm{SD}$ & Mean & SD & $t$ & $p$ & Cohen's $d$ \\
\hline & \multicolumn{7}{|c|}{ Language } \\
\hline & \multicolumn{2}{|c|}{$1^{\text {st }}$ language $(\mathrm{N}=46)$} & \multicolumn{2}{|c|}{$2^{\text {nd }}$ language $(\mathrm{N}=35)$} & & & \\
\hline $\mathrm{R}$ & 28.4 & 9.1 & 25.5 & 9.0 & 3.448 & 0.042 & 0.32 \\
\hline $\mathrm{I}$ & 22.8 & 9.5 & 20.7 & 9.2 & 0.967 & 0.337 & 0.22 \\
\hline A & 17.9 & 9.1 & 20.9 & 10.8 & -2.585 & 0.053 & 0.30 \\
\hline $\mathrm{S}$ & 27.1 & 7.0 & 28.5 & 9.9 & -0.775 & 0.441 & 0.16 \\
\hline $\mathrm{E}$ & 24.4 & 8.8 & 23.8 & 9.0 & 0.304 & 0.762 & 0.07 \\
\hline \multirow[t]{3}{*}{$\mathrm{C}$} & 20.6 & 8.9 & 20.6 & 9.1 & 0.233 & 0.816 & 0.00 \\
\hline & \multicolumn{7}{|c|}{ Seniority } \\
\hline & \multicolumn{2}{|c|}{ Junior divers $(N=69)$} & \multicolumn{2}{|c|}{ Senior divers $(N=12)$} & & & \\
\hline $\mathrm{R}$ & 26.9 & 9.7 & 30.4 & 8.8 & -1.262 & 0.225 & 0.38 \\
\hline I & 21.9 & 9.7 & 22.1 & 7.3 & -0.095 & 0.925 & $<0.01$ \\
\hline A & 20.7 & 10.7 & 12.2 & 8.2 & 3.170 & $0.005^{*}$ & 0.89 \\
\hline $\mathrm{S}$ & 28.5 & 8.5 & 23.0 & 5.3 & 3.020 & $0.006^{*}$ & 0.78 \\
\hline $\mathrm{E}$ & 24.6 & 9.1 & 21.8 & 6.9 & 1.212 & 0.241 & 0.35 \\
\hline $\mathrm{C}$ & 20.7 & 9.4 & 18.4 & 5.8 & 1.144 & 0.265 & 0.29 \\
\hline
\end{tabular}




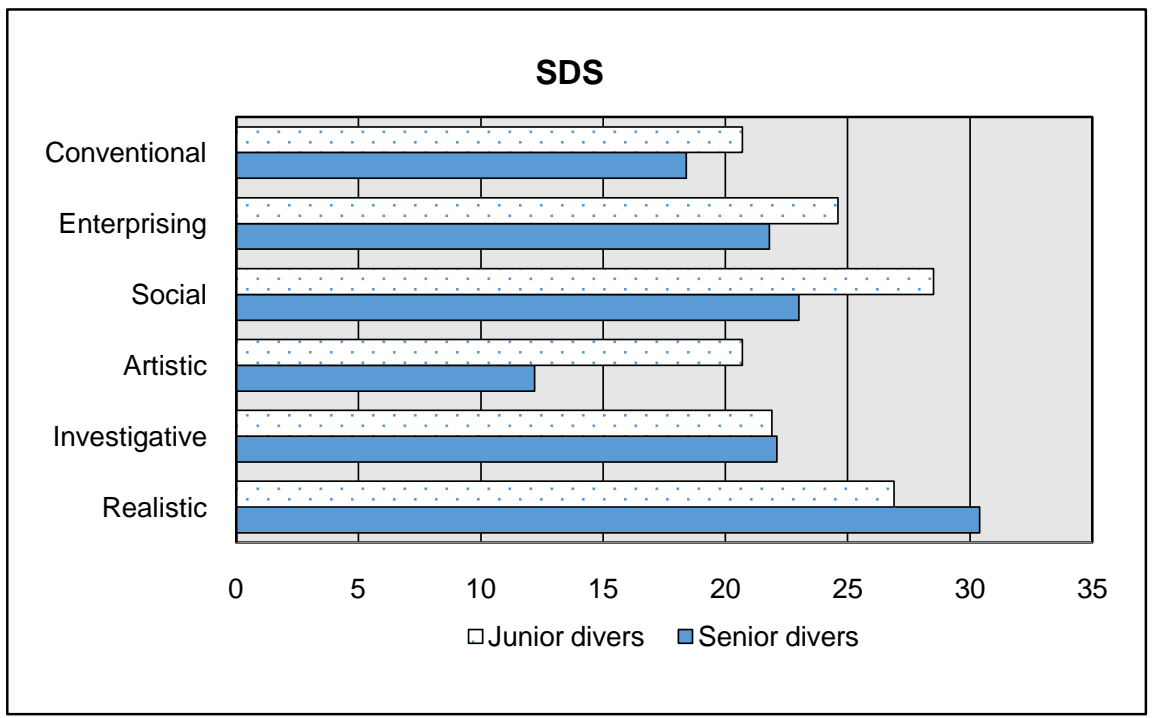

Figure 2. Personality type profiles for junior and senior divers.

diving since high school. Of this group, nine had family members or friends who were currently or previously involved in the diving industry or the armed forces. The second category of divers $(\mathrm{N}=39)$ learned about this employment opportunity when navy recruiters came to swimming or lifesaving clubs in their communities. Of this 39,14 were members of such clubs, while 25 heard about the recruiters and attended with the hope of securing employment. None considered naval diving as a career prior to this event. They were mostly from coastal provinces. The third category of divers $(\mathrm{N}=7)$ heard through their schools that the SAN was recruiting, and applied for any position without knowing much about the navy or what divers did. They came mostly from inland provinces.

\section{Discussion}

SAN clearance divers report a 3-digit code of S-R-E. However, poor differentiation may limit the usefulness of the code. Consistency was also poor, and congruence appeared sub-optimal. The 3-digit code differed from what was expected, referring in particular to the high prominence of $S$. The prominence of an $S$ personality type in an $\mathrm{R}$ environment initially appeared incongruent, given that S types are summarised [7] [17] as tending to avoid working with machines and other activities demanded by realistic occupations and situations, and have an aversion to ordered, systematic activities, instead preferring to help people through discussion and teamwork. To understand the apparent incongruence, two issues need to be considered:

Firstly, the SADO could simply be outdated, a concern raised previously [4]. Also, navy diving was not actually listed in the SADO, and only related occupations were used for comparison. Further, the SDS edition used in this study could be invalid for local populations, given the different cultural and language backgrounds of South Africans, a concern also raised previously [4] [19].

Secondly, socio-economic dynamics may influence the findings: The difficulty 
in securing employment has been noted earlier, and the interview data suggests that the majority of the divers did not specifically seek out navy diving per se as a career. They appeared to select this occupational field based on opportunity rather than an interest-personality fit. Given the dearth of employment prospects, and the pressure on young people to provide for their families [20] [21], any employment opportunity-whether in a field of interest or not-may come to be seen as a possible career.

Further to this is an education system that-at least for poorer resourced schools-does not necessarily allow for the development of good career selfknowledge. This may be reflected in the lack of differentiation reported in the current sample, where many participants came from remote and rural communities. Senior divers posed a somewhat more differentiated 3-digit profile, suggesting that as individuals developed in their own career, those with less compatible profiles may find alternative career fields to pursue.

In spite of the seemingly poor person-environment congruence, participants all appeared to be successful in their field, as indicated by working for at least two years in their posts. To understand this, two issues need again to be considered:

Firstly, the association of $\mathrm{R}$ to the environment of diving has been reviewed, and appears an obvious fit. While the prominence of $S$ initially seemed at odds, previous studies have observed strong group orientated personality characteristics among SAN divers [16], which was attributed to national contexts [22]: SAN divers from an arguably more collectivist society may be more interpersonally orientated than navy divers from more individualist (i.e. western) societies. While it could be reasoned that $S$ may then reflect national characteristics, it could also be a SAN diving-specific characteristic: SAN diving is organised into Operational Diving Teams, and diving is always done in small teams, and thus those individuals with higher interpersonal interest might adapt easier in this team context.

Secondly, it could reflect back to the socio-economic situation. Young divers may feel under pressure to adapt to the environment to maintain their employment contracts, and may be persevering in spite of a poor person-environment fit. The economic motivation may lead navy divers to learn to live with their person-work incongruence, and possibly find other avenues to live out their social and other interests. In spite of apparent code incongruence, divers still adjusted well, suggesting that they can overcome the seemingly poor match through either motivation or socialisation into the field.

To meet local ethics requirements, this study used an older edition of the inventory, namely the SA version which dates back to 1997, and the SADO, which dates back to 1987. It might be time for a SA adaptation of the most recent edition of the SDS (currently the SDS, Form $R, 5^{\text {th }} E d$.), and an updating of the SADO.

A potential strength of the study-administering the SDS to divers with at least two years' service in their vocational environment-may also be a limita- 
tion. Their personality profiles could reflect some form of socialisation or adaptation into the norms of that environment, rather than their own original personality type. This leaves the question whether the S-R-E code is the product of socialisation and/or adaptation, where personality expression developed or adapted to match the environment, as opposed to whether it is a product of the attrition of less-than-optimal matched individuals. Future studies could administer the SDS on entry into the diving branch, and then again after two years, to investigate whether there is a change across time, and whether there is a difference between those who remain in the branch and those who exit early.

Lastly, this pilot study relied on a single measure administered to a single vocational group. The result is therefore only suggestive, and future studies are required for replication with other vocational groups, as well as the inclusion of other measures and in other developing countries.

\section{Conclusions}

This study suggests that some of the assumptions underlying vocational assessment may be based on premises that might not hold in economies with less than full employment. The use of vocational guidance scales like the SDS in developing countries thus remains problematic.

This case study with SAN divers suggests that the SDS code for navy diving may reflect other considerations rather than an ideal person-environment fit. In this case it appears that SA's context as developing country, with its associated high rates of unemployment, might play a significant role when it comes to vocational placement and the use of testing to do so. In particular, constrained labour markets may not grant the assumption that people who are vocationally suited to an occupation are the ones who gravitate towards such an occupation.

It might therefore be inappropriate to use SDS codes (and possibly related vocational guidance instruments) uncritically in contexts where socio-economic considerations may outweigh personality characteristics in career choices. In developing countries, career choice may reflect socio-economic dynamics rather than an expression of personality type.

\section{References}

[1] Brown, S.D. and Lent, R.W. (2012) Career Development and Counseling: Putting Theory and Research to Work. John Wiley \& Sons, Inc., Hoboken.

[2] Psychological Assessment Resources (n.d.) Self-Directed Search. http://www.self-directed-search.com

[3] Morgan, B., de Bruin, G.P. and de Bruin, K. (2015) Constructing Holland's Hexagon in South Africa. Journal of Career Assessment, 23, 493-511. https://doi.org/10.1177/1069072714547615

[4] Watson, M.A., Foxcroft, C.D. and Allen, L.J. (2007) Tracking Holland Interest Codes: The Case of South African Field Guides. Australian Journal of Career Development, 16, 51-59. https://doi.org/10.1177/103841620701600208

[5] Schaab, B. and Dressel, J.D. (2004) What Personality Characteristics Do Digitally Competent Soldiers Have in Common? Proceedings of the Second Human Per- 
formance, Situation Awareness and Automation Conference, 22-25 March 2004, Daytona Beach, 259-260.

[6] Upperman, P.J. and Church, A.T. (1995) Investigating Holland's Typological Theory with Army Occupational Specialities. Journal of Vocational Behavior, 47, 61-95. https://doi.org/10.1006/jvbe.1995.1029

[7] Holland, J.L. (1997) Making Vocational Choices: A Theory of Vocational Personalities and Work Environments. 3rd Edition, Psychological Assessment Resources, Odessa.

[8] Gevers, J., Du Toit, R. and Harilall, R. (1997) Manual for the Self-Directed Search Questionnaire. Human Science Research Council, Pretoria.

[9] Taljaard, J.J. and Von Mollendorf, J.W. (1987) The South African Dictionary of Occupations. Konsensus Publishers, Pretoria.

[10] Messer, M.A., Greene, J.A. and Holland, J.L. (2013) The Veterans and Military Occupations Finder. Psychological Assessment Resources, Lutz.

[11] Hogan, J. and Hogan, R. (1989) Noncognitive Predictors of Performance during Explosive Ordnance Disposal Training. Military Psychology, 1, 117-133. https://doi.org/10.1207/s15327876mp0103_1

[12] Statistics South Africa (2016) Quarterly Labour Force Survey. Statistical Release P0211. http://www.statssa.gov.za/publications/P0211/P02111stQuarter2016.pdf

[13] SAPA (2014) 170000 Applicants for KZN Traffic Jobs. http://www.iol.co.za/news/south-africa/kwazulu-natal/170-000-applicants-for-kzn-t $\underline{\text { raffic-jobs- } 1634718}$

[14] SA Navy (2016) SA Navy Recruitment Process Unpacked. http://www.navy.mil.za/sancareers/SA\%20Navy\%20Recruitment\%20process\%20un packed.pdf

[15] SA Navy (2016) Career opportunities in the SA Navy. http://www.navy.mil.za/SANcareers/divers.htm

[16] Van Wijk, C.H. and Waters, A.H. (2001) Personality Characteristics of South African Navy Divers. Undersea and Hyperbaric Medicine, 28, 25-30.

[17] Allen, L.J. (2005) The Appropriateness of Holland's Interest Code Typology for South African Field Guides. Unpublished Master's Thesis, Nelson Mandela Metropolitan University, Port Elizabeth.

[18] Holland, J.L. (1985) Professional Manual for the Self-Directed Search. Revised Edition, Psychological Assessment Resources, Washington DC.

[19] Du Toit, R. and de Bruin, G.P. (2002) The Structural Validity of Holland's R-I-A-SE-C Model of Vocational Personality Types for Young Black South African Men and Women. Journal of Career Assessment, 10, 62-77. https://doi.org/10.1177/1069072702010001004

[20] Birnbaum, S. (2015) In South Africa, It's Called Black Tax. Development and Education, PRI.

http://www.pri.org/stories/2015-11-24/south-africa-its-called-black-tax

[21] Ratlebjane, M. (2015) How “Black Tax" Cripples Our Youth’s Aspirations. Mail \& Guardian.

http://mg.co.za/article/2015-10-29-how-black-tax-cripples-our-youths-aspirations

[22] Picano, J.J., Williams, T.J. and Roland, R.R. (2006) Assessment and Selection of High-Risk Operational Personnel. In: Kennedy, C.H. and Zillmer, E.A., Eds., Military Psychology, The Guilford Press, New York, 353-370. 
Submit or recommend next manuscript to SCIRP and we will provide best service for you:

Accepting pre-submission inquiries through Email, Facebook, LinkedIn, Twitter, etc. A wide selection of journals (inclusive of 9 subjects, more than 200 journals)

Providing 24-hour high-quality service

User-friendly online submission system

Fair and swift peer-review system

Efficient typesetting and proofreading procedure

Display of the result of downloads and visits, as well as the number of cited articles Maximum dissemination of your research work

Submit your manuscript at: http://papersubmission.scirp.org/

Or contact jss@scirp.org 